\title{
Theoretical and Practical Aspects of Logistic Quality Management System Documentation Development Process
}

\author{
Linas Šaulinskas ${ }^{1}$, Narimantas Kazimieras Paliulis² ${ }^{2}$ leva Meidutè-Kavaliauskiené ${ }^{2}$
}

\begin{abstract}
This paper addresses aspects of logistics quality management system documentation development and suggests models for quality management system documentation development, documentation hierarchical systems and authorization approval. It also identifies logistic processes and a responsibilities model and a detailed document development and approval process that can be practically applied. Our results are based upon an analysis of advanced Lithuanian and foreign corporate business practices, a review of current literature and recommendations for quality management system standards.
\end{abstract}

KEY WORDS: $\quad$ quality; standard; logistic process; process map; process hierarchy; document development; document hierarchy; optimization

JEL Classification: D20; D23; D80; L22; M10

'Mykolas Riomeris University, Lithuania; ${ }^{2}$ Vilnius Gediminas Technical University, Lithuania

\section{Introduction}

Dynamic changes in global markets, increasing globalization, growing consumer demand for production and service quality are common challenges that are forced upon today's companies (Bititci et al., 2011; Ronnback, Witell, 2008; Yeung, 2008). According to Bennett, Kerr (1996), Fuentes-Fuentes et al. (2007), Karatepe, Karadasa (2012), Kuei, Lu (2013), Lam et al. (2011) and Pabedinskaite, Vitkauskas (2011), to successfully maintain a competitive advantage, companies are forced to focus on improvement of production and service quality. According to a majority of authors (Hoang et al., 2010; Martinez-Costa et al., 2009; Olayonwa et al., 2012; Sampaio et al., 2009; Zakuana et al., 2010),

Correspondence concerning this article should be addressed to: leva Meidutè-Kavaliauskienè, Vilnius Gediminas Technical University, Faculty of Business Management, 11 Sauletekio al., Vilnius, LT-10223. e-mail: ieva.meidute@vgtu.lt an internationally recognized guarantee of quality is a company's certification of compliance with the ISO 9000 series of standards. Companies that are certified, and publicly proclaim that fact, have a competitive advantage. Yet, certification does not guarantee quality; rather, it shows that the company has formalized business processes (Foster, Ogden, 2008; Kannan, Tan, 2007; Pabedinskaite, Vitkauskas, 2010; Yaacob, 2009). In practice, some companies seek to merely implement a formal quality management system to gain certification. Accreditation and introduction of a standard will not bring radical changes or benefits because the entire company's efforts will be directed towards the formalization of business processes and documentation, rather than on improvement (Fuentes-Fuentes et al., 2007; Gorla et al., 2010). Criticism of the ISO 9000 series of standards is attributed to a relatively large volume of work associated with process documentation (Naor et al., 2008; Olayonwa et al., 2012; Rocha 


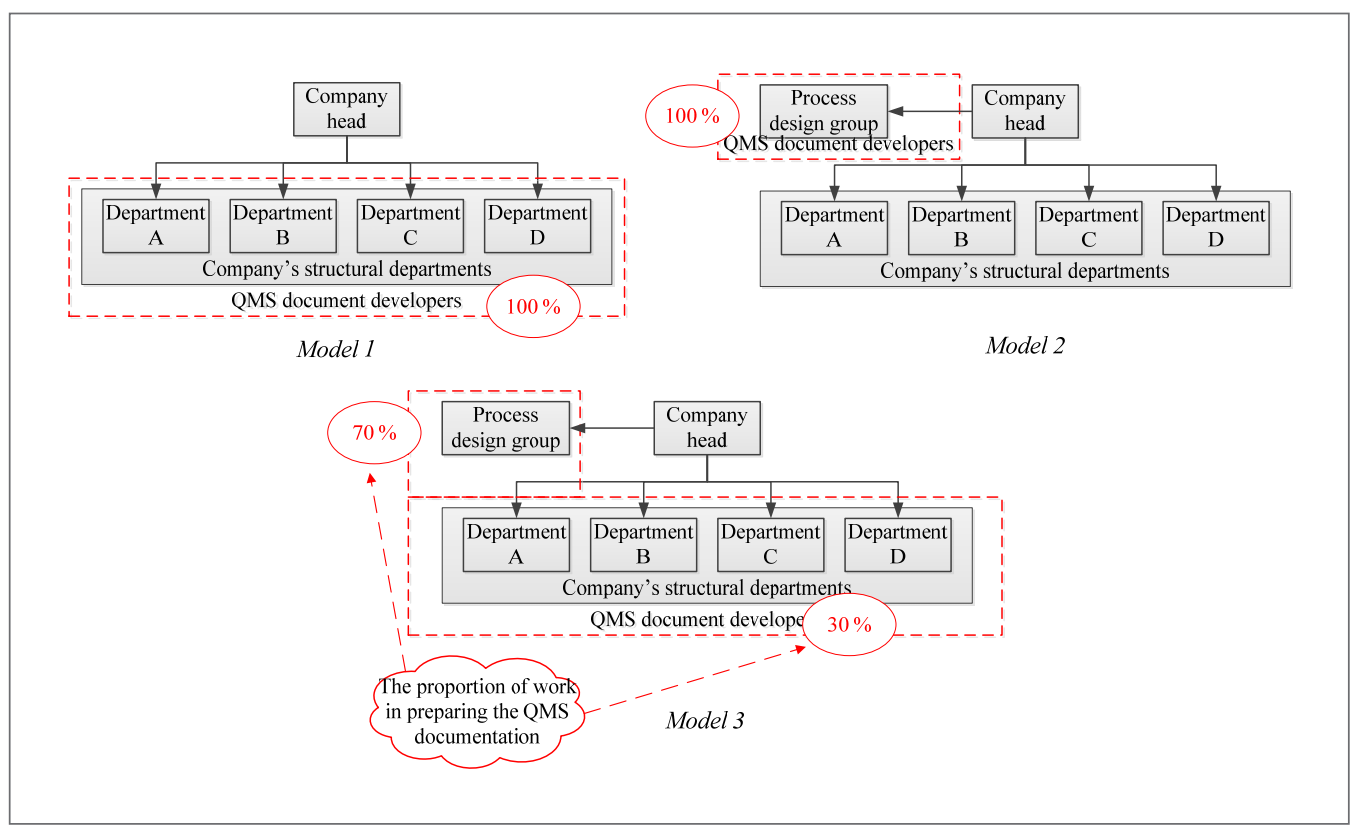

Figure 1. QMS document development models

et al., 2007). However, should a company seek to improve performance quality by regulating the processes and procedures with instructions, standards and other documents (hereinafter QMS documents), the effort always pays off. If the company did not have such documentation, and processes have not been addressed adequately, the improvements will move the company from a disordered state to a more structured system, enormously benefiting the company, its customers and associates (Talib et al., 2011). Implementation of a quality management system (hereinafter QMS) that meets the ISO 9000 series requirements helps to reduce the cost and increase the volume of production, which increases demand for the product (Carmignani, 2009; Davidavičienè, Meidutė, 2011; Kim et al., 2010; Kuei et al., 2008; Loke et al., 2012; Pabedinskaitè, Vitkauskas, 2010, 2011; Zhu et al., 2012).

Often corporate executives perceive the quality control system as merely a vast collection of documentation that leads to a vast amount of bureaucracy (Breja et al., 2011). However, the ISO standards do not require creating such a situation. Standards contain recommendations as to which documents should be included; however, the volume and complexity of such documents depends on the competence of the developers and level of organization within the process (Breja et al., 2011; Naor et al., 2008; Rocha et al., 2007). The QMS document development labor costs can be reduced by normalizing the QMS implementation and documentation processes (Antony, 2006; Hoang et al., 2010). Therefore, this article aims at revealing the theoretical and practical aspects of the logistic process of QMS documentation development while helping enterprise executives make rational decisions when selecting appropriate QMS documentation development models, identifying the structure of the documents, preparing logistic processes maps of the enterprise and developing documented procedures to serve as a foundation for the successful introduction and operation of a quality management system. The study was conducted by applying a systematic, comparative and logical analysis and synthesis of the scientific literature, current regulations, standards and advanced Lithuanian and foreign companies' business experience.

\section{Major QMS document development models}

Scientific literature (Bennett, Kerr, 1996; Bititci et al., 2011; Foster, Ogden, 2008; Gorla, et al., 2010; Hoang et al., 2010; Kim et al., 2010; Kuei, Lu, 2013; Lam et 

Table 1. Comparative analysis of QMS document development models

\begin{tabular}{|c|c|c|c|}
\hline & Model I & Model II & Model III \\
\hline Structural department involvement & $\begin{array}{c}+ \\
\text { (100 percent) }\end{array}$ & - & $\begin{array}{c}+ \\
\text { (30 percent) }\end{array}$ \\
\hline Logistic processes design group involvement & - & $\begin{array}{c}+ \\
\text { (100 percent) }\end{array}$ & $\begin{array}{c}+ \\
\text { (70 percent) }\end{array}$ \\
\hline Necessary knowledge of the designed project & + & $\begin{array}{c}- \\
\text { (minimal) }\end{array}$ & + \\
\hline Necessary knowledge of the logistic process design & $\begin{array}{c}- \\
\text { (minimal) }\end{array}$ & + & + \\
\hline QMS document standardization and unification & - & + & + \\
\hline QMS document compatibility & - & + & + \\
\hline Review and control of the QMS document development logistic process & - & + & + \\
\hline
\end{tabular}

1), we can conclude that the QMS document development model that leverages both the Process Design Group and the structural unit employees is the optimal, organization-wide model.

As stated by Gorla et al. (2010), taking into account the increasing flow of information, which is changing and growing every year, and the ever growing complexity of technologies, it becomes impossible for a few people to cover the entire diversity of business processes. Thus, neither a single employee of a Process Design Group nor a structural unit employee developing QMS documents separately would be able to achieve the same results that could be achieved by developing the documents together. This proves the saying that "no one knows everything, everyone knows something". Therefore, integrating employees from the Process Design Group and structural departments into a single team, where everyone knows certain specific aspects, yields a better result. The outcome of a well-organized team is always stronger and better than the sum of the individual efforts of employees working separately; apparently, teamwork creates a synergetic effect. This idea is confirmed by our analysis of the leading companies that have implemented model III to achieve a maximum synergistic effect.

\section{QMS document development model}

To rationally utilize all of the advantages of the third model and eliminate the disadvantages, the QMS document development model is recommended (Figure 2). Initially, to improve the QMS document development logistic scheme, it is necessary to create a series of measures to ensure successful QMS document development and coordination and approval in dayto-day activities (standard preparatory procedures are required for implementation of the QMS document development model).

These procedures include five key elements: compilation of a business processes map, preparation of a responsibility model based on process types, establishing QMS documentation hierarchy and associated approval powers, classification and unification of QMS documents, and design and approval of QMS document development and approval processes. These elements should be performed by the Process Design Group or external consultants with the necessary knowledge of QMS document preparation peculiarities. Having standardized and unified QMS documents and the associated development processes, a technical platform is formed for structuring and describing business processes and their improvement and fusion into one logi$\mathrm{cal}$ and global chain of processes that eliminate process 


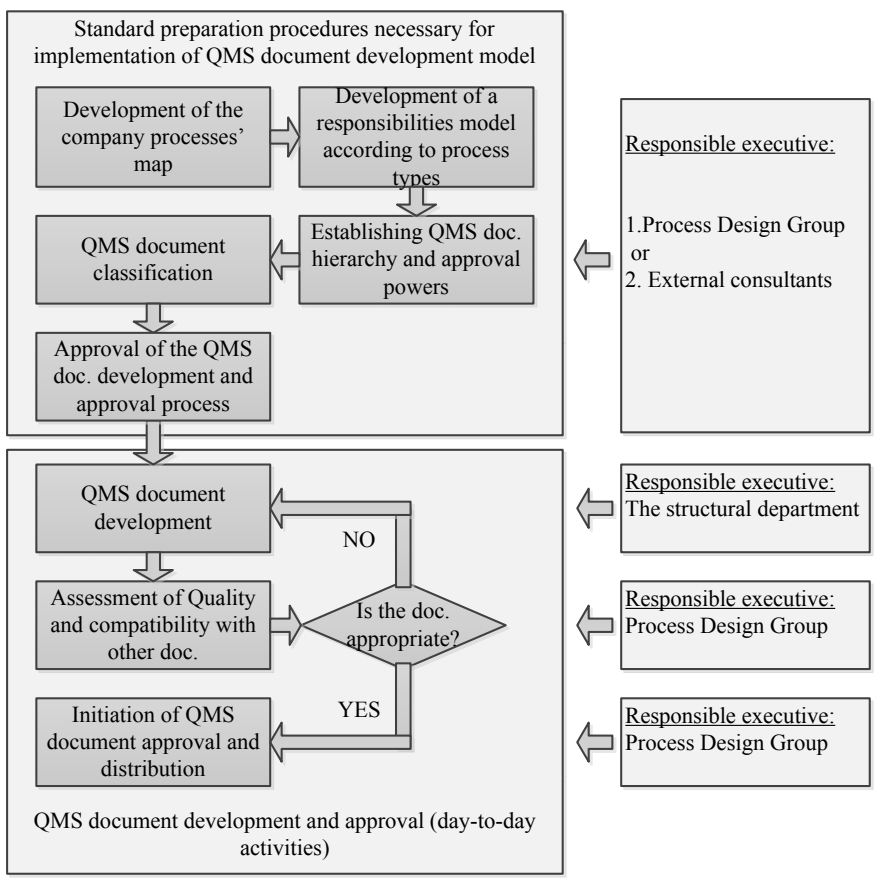

Figure 2. QMS document development model

overlap and drawbacks. Practical benefits of creating separate elements of a QMS document development model will now be discussed.

\section{Company processes map}

Scientific literature and current standards (MartinezCosta et al., 2009; Sampaio et al., 2009) for quality management systems recommend that companies identify critical processes, determine their implementation, define the logical sequence of these processes and their interactions, and define the productive performance of these processes, in addition to implementation of criteria and methods to ensure successful performance and management. Therefore, identification of critical processes and their sequence and interaction is one of the major aspects of a quality management system.

According to the current literature (Kuei et al., 2013; Lam et al., 2011; Martinez-Costa et al., 2009; Pabedinskaite, Vitkauskas, 2011; Ronnback, Witell,
2008; Sampaio et al., 2009; Zakuana et al., 2010), a company, with regard to operational specifications, is suggested to distinguish between four groups of processes: management processes (related to resource management), basic processes (related to products and services), support processes (designed to serve the basic and business processes) and general processes. "Management processes" consist of strategy development and quality management system management processes. "Basic Processes" govern service providing, purchasing, designing, marketing, and other similar processes. "Support processes" oversee personnel management, facility management, and other similar processes. "General processes" include activities that must be performed by everyone, for instance, document management, record management, etc. The number of groups of processes and their composition can vary depending on a company's needs. For example: marketing process can be attributed not to the 


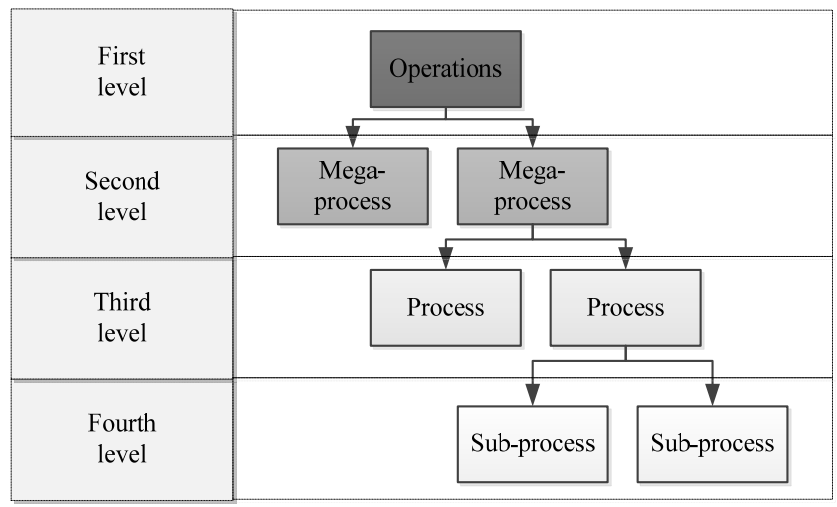

Figure 3. Process hierarchy diagram

basic processes, but rather to the support and general processes groups, whereas the general processes and support process groups, for the sake of clarity, are often combined into a common "support processes" group. Ultimately, the mix of groups depends on the peculiarities of a specific company and its needs.

Operationally, processes are often structured according to their significance and the level of detail within the process groups (Fuentes-Fuentes, et al., 2007; Kim et al., 2010). Business process management-starting with strategy and moving towards implementation-is based upon operations and process hierarchy, where one or several major processes (mega-processes) are divided into several lesser processes and are further divided into sub-processes-with the goal of describing company operations (Figure 3 ).

The first level of detail contains activities that are the basic business activities of the company. Companies can have anything from a few to several dozen of such activities.

The second level contains mega-processes that are the entirety of processes conducted by the company and are directed towards fulfilling the company's major aims.

The third level contains processes that are a consistent set of interrelated actions (procedures) and action phases (sub-processes), fulfillment of which creates a beneficial result for external or internal customers.
The fourth level contains the sub-processes, which are at the detailed procedural analysis level; the process components consist of a coherent sequence of actions, which have more than one implementation path.

Each company aims to develop a business process management and responsibilities model based on best practices, which can contribute to structured and efficient management definitions, basic and support operating processes, refined liabilities and constant development and improvement of the processes. One of the possible mega-process mapping examples is provided in Figure 4.

In the mega-process map provided (see Figure 4), the processes of the company are divided into three groups: management, business, and support activities. Each group distinguishes its main group-specific activities. The management group, for instance, is responsible for operations planning, internal control, internal audit, etc. The business group is entrusted with customer management, service management, service creation and development, sales channel development, etc. The support activities group oversees accounting and reporting, staff management, information systems management, etc. Each of these activities is described by the megaprocesses referred to in Figure 4. Afterwards, the mega-processes are broken down into processes, and the processes are further broken down into sub-processes. Each company determines the required amount of process hierarchy levels according to its needs. 


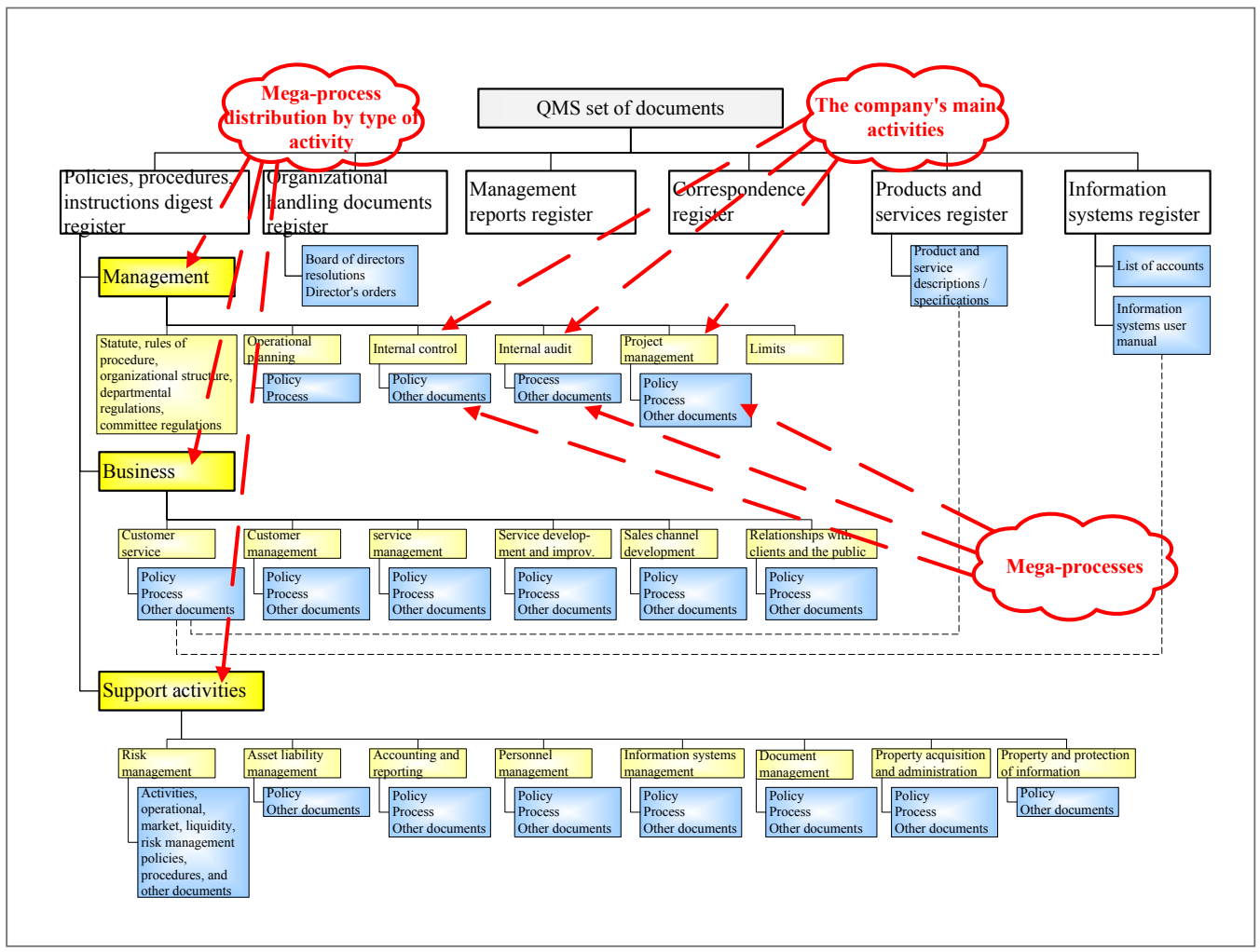

Figure 4. Mega-process map

While developing and implementing a quality management system for a specific company, it is imperative that process owners are assigned for the identified processes and that appropriate responsibilities are delegated to them. The process owner is a structural unit, which is responsible for the process design, its regulation and practical implementation (monitoring and control). An example of a responsibilities model according to process types is provided in Figure 5.

Processes of a customer-oriented enterprise can be divided into five levels, depending on the development level of the processes and their management level (Figure 6):

Level I - "the Beginning". At this level, processes are vague. There are no process performance evaluation indicators; the performance of processes is inconsistent, and success depends solely on the personal efforts of the staff.

Level II - "Management System Introduced". At this level, processes are defined using charts. Megaprocesses and processes are depicted using flow dia- grams with a legend and matrix structure; the subprocesses are defined using sub-process schemes. A process efficiency indicator system is introduced, and indicators are linked to customer needs and regular monitoring of the process quality is established.

Level III - "Consistent Management". At this level, main processes are standardized and integrated with each other and with external processes. The main focus is on activities and costs.

Level IV - "Predictable Processes". At this level, statistical methods are applied to ensure process quality.

Process performance quality is statistically stable and constantly meets customer's needs. Additionally, customer needs are identified proactively and changes are made in the processes.

Level V - "Optimized Processes". At this level, permanent process management and improvement is carried out. Process variability is minimized and flexibility is increased. 


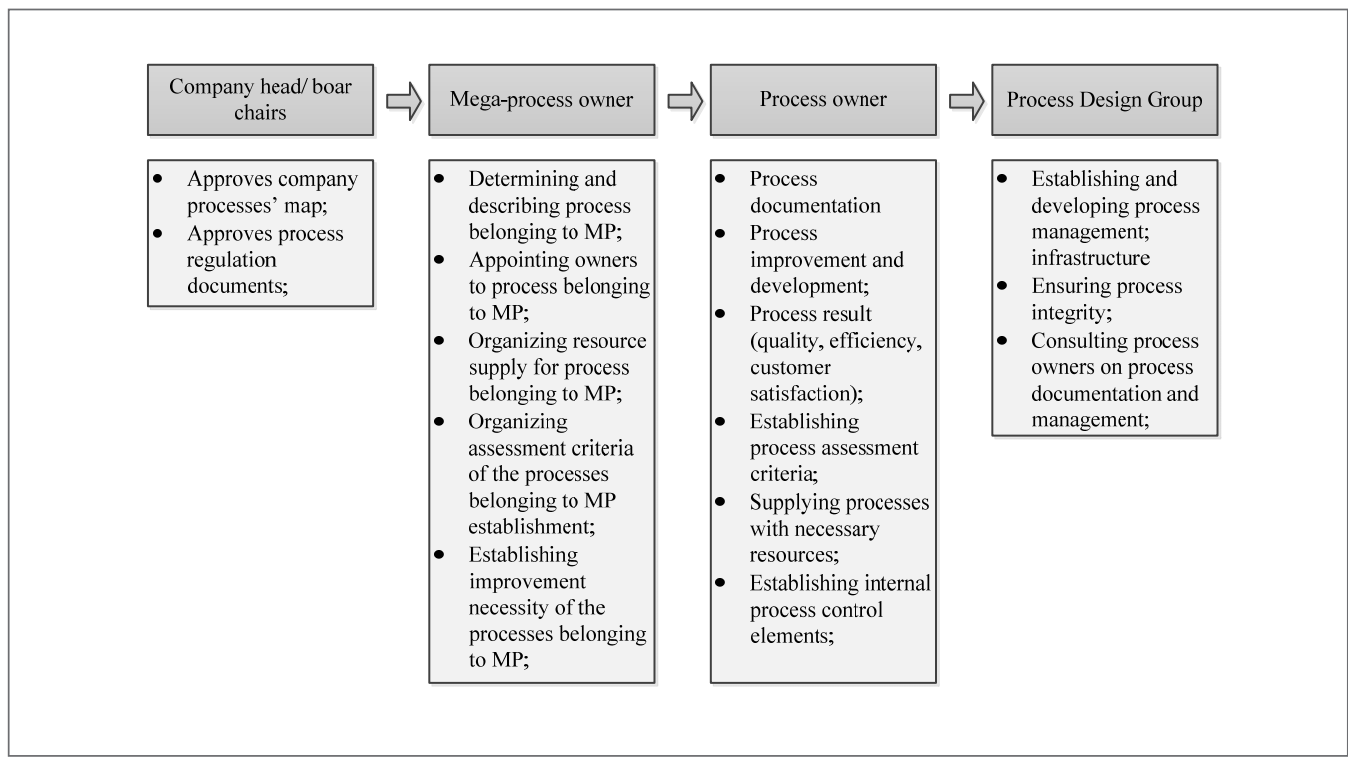

Figure 5. Example of a responsibilities model according to process types

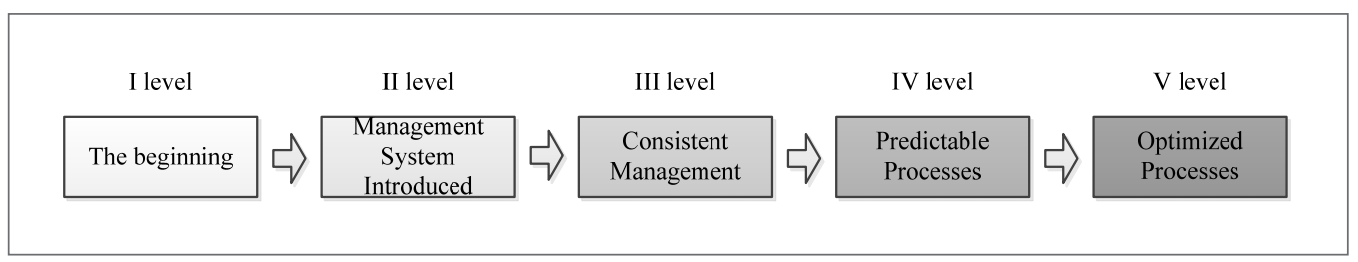

Figure 6. Process management levels of the client-oriented

Process approach emphasizes the necessity for business process identification and management. This is a relatively new approach to corporate management, which requires radical revision of the company's organizational structure, management performance indicators and control mechanisms. A single process diagram helps to create a system of documentation, establish procedures and necessary management documents, and identify information management procedures.

1. Benefits of process management can be defined by several aspects:

2. Operating clarity of the company. A clear-cut operating scheme is an effective enterprise management tool.

3. Perception of a company as a system. Identification of interrelated processes shows how employees and departments participate in common activities.
4. Process sequence optimization. Processes are analyzed in terms of benefits created by them, excluding phases that do not add value and seeking opportunities to increase process efficiency.

5. Staff coordination. Customer requirements and supplier capabilities are established for each process, and cooperation of different departments and functions is optimized.

6. Process efficiency assessment and constant improvement. According to established indicators, process efficiency is regularly evaluated and improved.

To summarize, it can be said that strategic measures have to be identified to increase the efficiency of each company. These measures would be directed towards centralization and optimization of business processes and fostering of a continuous improvement of culture. 


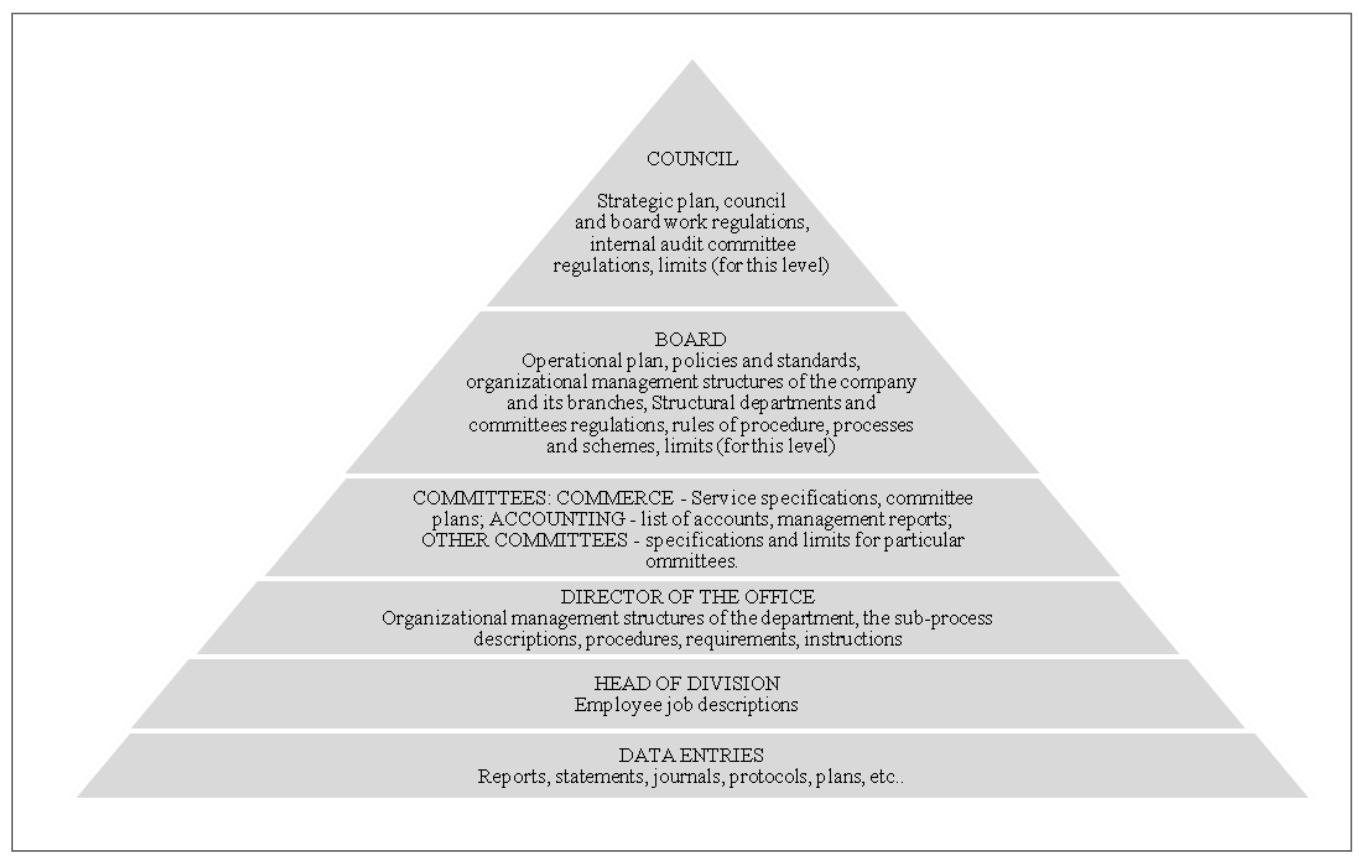

Figure 7. QMS documents hierarchy and powers of their approval

To achieve the long-term goals for each of company's operations efficiency, process management infrastructure needs to be addressed.

\section{Structure of QMS documents}

Company QMS documentation consists of the company's internal regulatory documents, which regulate the functions and powers of the departments and employees, flowcharts, management processes, actions or events that may affect fulfillment of the company's objectives, quality of a product / service / customer service and risk management or internal control assurance. The list of practically applied QMS documents is large and includes plans, labor regulations, policies, organization flowcharts, structural departments and committees' provisions, staff job descriptions, process diagrams, sub-process descriptions, instructions, standards, procedures, requirements and service specifications. Regardless of the diversity of QMS documents, they must make assumptions to ensure efficient operations within the company as well as on the outside. Documents support the following internal aspects of the company: effective process management, opportunities to objectively assess the documentation and perform the process audit, process improvement opportunities, appropriate establishment of staff powers and responsibilities, staff training efficiency, traceability of processes (possibility to determine service or process history according to the records) and the possibility to provide evidence of the processes that have taken place. QMS documents also support the following external aspects of the company: a possibility to demonstrate effective functioning of internal control system for external auditors, government and law enforcement offices and businesses associates.

Scientific literature (Antony, 2006; Breja et al., 2011; Kuei et al., 2013; Lam et al., 2011; Martinez-Costa et al., 2009; Pabedinskaite, Vitkauskas, 2011; Ronnback, Witell, 2008; Sampaio et al., 2009; Zakuana et al., 2010) provides a set of general requirements for QMS documentation. According to these sources, the QMS documents are usually divided into four levels:

- the first level documents - a quality manual, organizational structure, quality policy, division of duties and powers. At this level QMS documentation structure and general principles are set. 
- the second level documentation includes processes and procedures. It specifies how the activities are performed.

- the third level includes labor manuals, operating manuals, specifications.

- the fourth level includes various forms, records, etc.

As practice shows, the QMS documentation hierarchy, and the number of levels and types of QMS documentation may differ significantly depending on the size of the company, hierarchical levels of the organizational management structure of the enterprise, the nature of its operations and the objectives pursued, the complexity of processes and their interactions, and staff competence. Figure 7 includes one of the possible QMS documentation hierarchies and examples of the document approval powers. The QMS documents are divided into six levels in this scheme. This division can be applied to large-scale enterprises. Meanwhile, a small company can rely on a QMS documentation system consisting of only a few levels, such as a quality manual and procedures.

The highest level of the QMS documents hierarchy (managerial level) includes strategic documents: a strategic plan that covers the main directions of company activities and the expected outcomes of these directions as well as work regulations of the top management level. The second hierarchical level (board level) provides: operational plans, which cover the main directions of company activities and the expected outcomes of these directions for one year; company policy, which sets out the principal provisions necessary for the company to achieve objectives in particular fields; structural departments of the company and their subordinate relations are depicted in the organizational management flowcharts; their aims, functions, rights, duties, powers, and responsibilities of structural departments and committees are set in the provisions; and major processes of the enterprise are depicted in the process diagrams. At the third hierarchical level (committee level), committee governing documents are provided: accounts plan and product / service specifications, which define the product / service parameters, and their main features, specifications of particular committees, etc. The following documents are provided at the fourth level of the hierarchy (service level): sub-process descriptions, which regulate sub-processes and indicate who has to do what, why, when, by what means, and where. The process must include interrelated activities, have a beginning and an end, external or internal customers, and more than one employee has to participate in it. Both the process and the sub-process should always begin with input data and end with output data (results). Additionally, methodologies that define the performance methods are provided; guidelines with detailed description of complex, responsible, or hazardous work / operations; standards which set requirements for certain activities; requirements that impose compulsory requirements for the actions; and the actions that cannot be described as sub-processes. The lowest levels (branch and data record levels) include staff job descriptions, which establish their objectives, functions, rights, duties, powers and responsibilities, and journals, protocols, plans, reports and other records.

It is of great importance that the QMS documents are standardized and classified. Standardization of the QMS documentation makes it possible to shorten the duration of the QMS document development and ensure document comparability, and QMS document classification (based on document registers, file groups, files, types of documents, etc.) ensures convenient retrieval options. As most of the documents in modern enterprises have electronic forms, it makes sense to determine the relationship between the QMS documents to make it easy to find related documents if they are needed. This is especially important when new QMS documents are being developed or existing documents are modified and when it is necessary to ensure traceability of related documents and consistency between them. Despite the abundance of QMS documents and the importance of each and every document, the primary focus is on identification and development of a company's processes and sub-processes because, as practice shows, these documents are the basis for development of all the other QMS documentation.

\section{QMS document logistic development and approval process}

Document management is closely associated with international ISO standards, as it is one of the most important aspects of the quality management system. The quality of the documents, to a great extent, determines the success of the quality assurance and management 


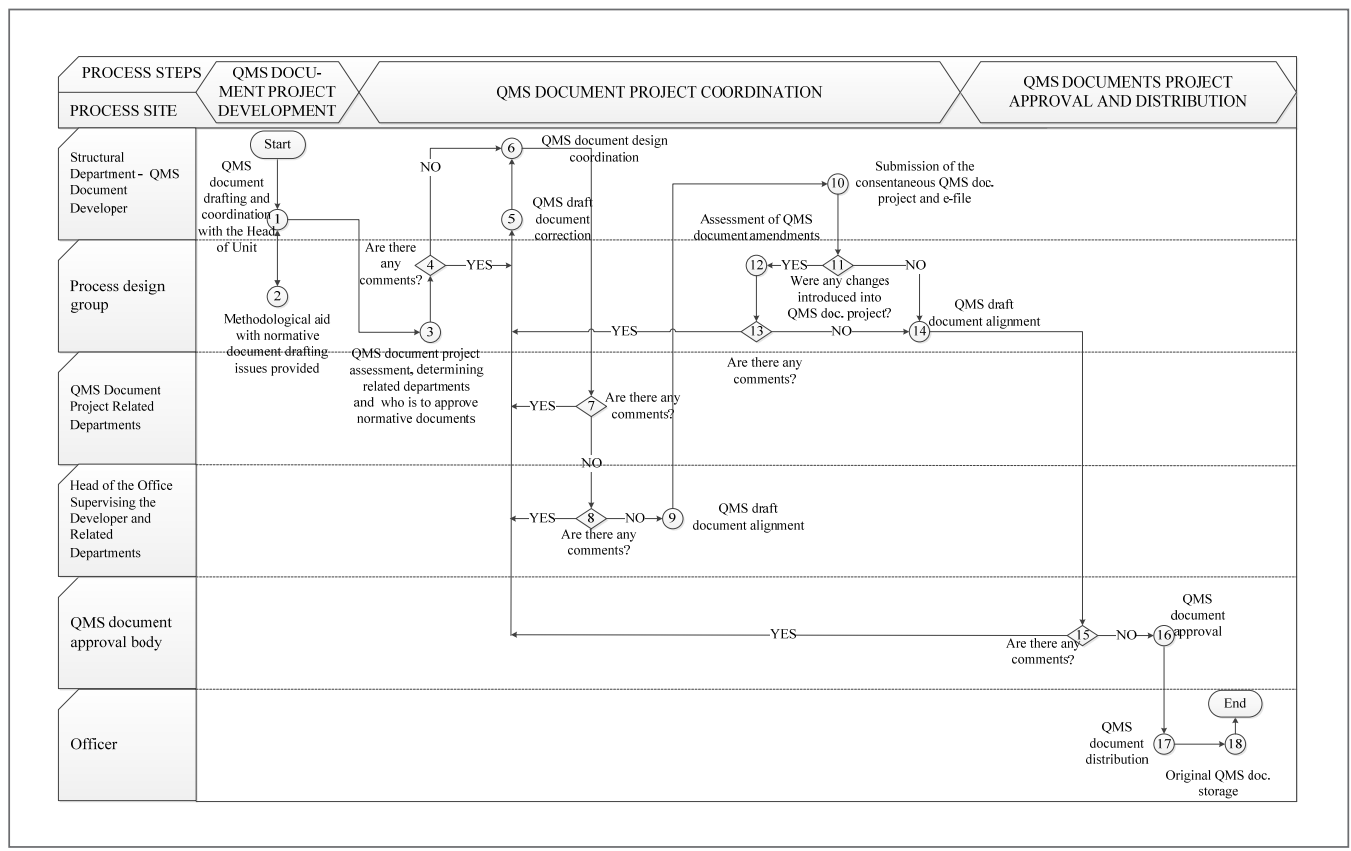

Figure 8. QMS document logistic development and approval process

in the company (Sampaio et al., 2009; Tapiero, 2006). The international ISO standards indicate that document management procedures, which would regulate and describe major quality management aspects, have to be prepared (Martinez-Costa et al., 2009). These include approval of document adequacy prior to publishing; analysis, and if necessary updating and their subsequent approval; ensuring document amendment version control, traceability, and safekeeping; etc. A standardized document management process makes it possible to reduce labor costs and time spent. QMS documents, depending on their nature and importance and taking into consideration the QMS documentation hierarchy (Figure 8), are developed, coordinated, and approved by a certain level of corporate governing body: the company council, the board, the CEO, service directors, etc. The department developing the QMS document has to ensure that process activities coordinated by it match the processes and activities described in the coordinated QMS documents. A detailed process of QMS document development (with coordination and approval) or appropriate modifications of the process can be applied in companies introducing quality management systems.
Development of the QMS documentation plan. It is appropriate for each structural department of the company to perform an assessment of the coordinated QMS documents and to determine whether they need amendment at least once a year. While preparing its action plan for the upcoming year, the structural department should record all the QMS documents that are planned to change in that department or along with other departments, indicating the authors of the documents and desirable deadlines for the development of the QMS documents. QMS document development plans prepared by the structural departments are submitted to the Process Design Group, which summarizes the plans received from the departments and prepares a general QMS document development plan for the upcoming year on an organization-wide scale.

QMS document drafting. The author of the QMS document prepares the primary QMS document draft in accordance with the methodology and requirements (for the descriptive part of the QMS document, diagrams, forms, etc.) developed by the Process Design Group. The Process Design Group consults the author of the QMS document, provides him/her with methodological assistance on issues related to QMS document development. 
Conformation and approval of the QMS document. The author of the QMS document submits the prepared QMS document project to the Process Design Group, which assesses the level of the QMS document development (with respect to rationality and quality), its compatibility with other relevant QMS documents, compliance with the standards and other established requirements, and establishes the departments with which the QMS document project is to be harmonized. The Process Design Group provides comments to the author regarding the QMS document project, the author introduces amendments to the QMS document project and harmonizes it with concerned departments (whose activities are described in the QMS document project) and departments governing specific issues: the legal department, the department of internal auditing, the risk assessment department, etc.

The authors of the document submit the confirmed QMS document project to the Process Design Group, which proposes it for approval. Upon approving the QMS document, it is passed on to the office or is returned to the author so that the latter can make amendments to it upon considering the comments.

Distribution and storage of the QMS documents. The office distributes the QMS document to all the concerned departments. In modern enterprises, QMS documents in an electronic file are usually placed in the document management databases, and the concerned departments are informed of the newly approved QMS document via the information systems. Approved QMS documents or any hard copies with their amendments, along with approving documents, are stored in the company office in accordance with company procedures.

\section{The Final Part}

Today, it is more common for companies operating in the market to pay particular attention to the management of their processes, in particular to the quality assurance of their activities. More and more company heads understand that implementation of a quality management system will create preconditions for the use of more efficient processes in their businesses. The documentation that describes them will ensure proper staff performance. This will reduce the number of dissatisfied customers and company staff. Customer satisfaction is a key indicator that shows a company's operational efficiency. Therefore, it is clear that the company that improves its performance quality and appropriately regulates business processes by introducing new standards can successfully develop business, thereby increasing its competitive advantage. Support, successful functioning, efficiency and performance issues of the quality management system are the problems encountered by companies that do not want to boast of having an international certificate but rather have a management system as a tool for successful quality service management. In difficult economic situations, the quality management system becomes even more valuable and more essential for a company than in a time of economic upswing. Clearly, in this situation an introduction of the system requires personal responsibility of employees for the changes in progress as well as their understanding, whereas management is required to organize transparent and smooth teamwork. The shortcomings of teamwork in the organization are very clearly observed during the process of quality system introduction, and successful functioning of the system is hardly possible without teamwork. The quality management system itself, according to the ISO standards, requires constant improvement of the processes in the enterprise.

An efficient QMS documentation management process ensures that if a non-standard situation occurs, employees will act exactly as needed and make appropriate decisions. Due to the described procedures employee training costs are reduced, as employee duties and powers are stated in the procedures in a very detailed way. If work is organized in accordance with the procedures, the employee undergoes less stress at work, which results improved self-esteem as a member of the community and satisfaction with his activities. A quality management system is a beneficial motivational tool; if employees know their common goal, they try to achieve it more efficiently.

The company that operates in accordance with the international ISO standards creates additional added value with its services, which is particularly important for the whole external environment-customers, associates and other institutions. Introduction of the quality management system in accordance with ISO standards in the company has clear benefits: it helps to achieve the set aims and implement company policy, improves the image of the organization and cus- 
tomers and partners' opinions, helps to reduce costs, optimizes performance and manages risk. However, it also has temporary drawbacks: staff resistance and standard maintenance costs. As practice shows, the system fully demonstrates its effectiveness during the third and fourth years of its existence in the company. This fact clearly demands the members of the company show loyalty to the company policies and that employees focus on the goals.

\section{Conclusions and Suggestions}

Having analyzed QMS document development models and established their advantages and disadvantages, an original logistic document development model can be proposed. The most effective is the model that involves employees of the structural and specialized (responsible for the process design procedures) departments in development of the QMS documents. In such a case, knowledge of the Process Design Group employees of the process design, standardization and unifying, and the structural department employees who are involved in a particular process, allows the company to achieve maximum synergy while describing, redesigning presenting or creating a new process. This is confirmed by the analysis of an advanced company's experience, and application of this model leads to a maximum synergetic effect. The article discusses aspects of quality management system documentation development and the management process, as well as suggests a quality management system document development model, which comprises the quality management system document hierarchy and their approval powers models, process and responsibilities model, detailed document development and approval process, and assumptions to reduce QMS document development labor and time costs.

In a QMS documentation hierarchy, the number of levels and types of QMS documentation may differ significantly depending on the size of the company, the hierarchical levels of the organizational management structure of the enterprise, the nature of its operations and the objectives pursued, the complexity of processes and their interactions and staff competence. Strategic measures have to be foreseen to increase the efficiency of each company. These measures would be directed towards centralization and optimization of business processes. To achieve the long-term goals set for each company's operations efficiency, the need to introduce a process management infrastructure arises, for instance, to prepare a company process map and to compile responsibility models according to process types and manage these processes depending on their development level. Based on recommendations within the international ISO standards and QMS document development model, a QMS document development, conformation and approval logistic process has been specified, the principles of which can be applied in companies introducing quality management systems. Every company has a certain management system, which comprises major aspects of its field. Usually, companies have official or unofficial rules or a set order of tasks that is implemented in day-to-day activities. It does not matter what type of system it is, what matters is that it has to function as effectively as possible so that company resources are used optimally, processes are designed to achieve the set aims and the quality of goods produced by the company or services provided are on the highest level possible.

\section{References}

Antony, J. (2006). Six sigma for service processes. Business Process Management Journal, 12 (2), 234-248.

Bennett, L. M., Kerr, M. A. (1996). A systems approach to the implementation of total quality management. Total Quality Management and Business Excellence, 7 (6), 631-666.

Bititci, U. S., Ackermann, F., Ates, A., Davies, J. D., Gibb, S., MacBryde, J., Mackay, D., Maguire, C., van der Meer, R., \& Shafti, F. (2011). Managerial processes: an operations management perspective towards dynamic capabilities. Production Planning \& Control: The Management of Operations, 22 (2), 157-173.

Breja, S. K., Banwet, D. K., Iyer, K. C. (2011). Quality strategy for transformation: A case study. The TQM Journal, 23 (1), 5-20.

Carmignani, G. (2009). Supply chain and quality management: the definition of a standard to implement a process management system in a supply chain. Business Process Management Journal, 15 (3), 395 - 407

Davidavičienė, V., Meidute, I. (2011). Quality of elogistics in e-commerce: consumer perception. In A. Kocourek (Ed.), Proceedings of the 10th Inter- 
national Conference "Liberec Economic Forum 2011". 19th - 20th September 2011 (pp. 90-99). Liberec: Technical University of Liberec.

Foster, S. T., Ogden, J. (2008). On differences in how operations and supply chain managers approach quality management. International Journal of Production Research, 46 (24), 6945-6961.

Fuentes-Fuentes, M. M., Lorens-Montes, F. J., Albacete-Saez, C. A. (2007). Quality management implementation across different scenarios of competitive structure: An empirical investigation. International Journal of Production Research, 45 (13), 2975-2995.

Gorla, N., Somers, T. M., Wong, B. (2010). Organizational impact of system quality, information quality, and service quality. Journal of Strategic Information Systems, 19 (3), 207-228.

Hoang, D. T., Igel, B., Laosirihongthong, T. (2010). Total quality management (TQM) strategy and organisational characteristics: Evidence from a recent WTO member. Total Quality Management \& Business Excellence, 21 (9), 931-951.

Kannan, V. R., Tan, K. C. (2007). The impact of operational quality: A supply chain view. Supply Chain Management: An International Journal, 12 (1), 14-19.

Karatepe, O. M., Karadasa, G. (2012). The effect of management commitment to service quality on job embeddedness and performance outcomes. Journal of Business Economics and Management, 13 (4), 614-636.

Kim, D. Y., Kumar, V., Murphy, S. A. (2010). European foundation for quality management business excellence model. International Journal of Quality and Reliability Management, 27 (6), 684-701.

Kuei, C. H., Lu, M. H. (2013). Integrating quality management principles into sustainability management. Total Quality Management \& Business Excellence, 24 (1-2), 62-78.

Kuei, C. H., Madu, C. N., Lin, C. (2008). Implementing supply chain quality management. Total Quality Management and Business Excellence, 19 (11), 1127-1141.

Lam, S. Y, Lee, V. H, Ooi, K. B, Lin, B. (2011). The relationship between TQM, learning orientation and market performance in service organisations: An empirical analysis. Total Quality Management \& Business Excellence, 22 (12), 1277-1297.
Loke, S. P., Downe, A. G., Sambasivan, M., Khalid, K. (2012). A structural approach to integrating total quality management and knowledge management with supply chain learning. Journal of Business Economics and Management, 13 (4), 776-800.

Martínez-Costa, M., Choi, T. Y., Martínez-García, J. A., Martínez-Lorente, A. R. (2009). ISO 9001/1994, ISO 9001/2000 and TQM: The performance debate revisited. Journal of Operations Management, 27 (6), 495-511.

Naor, M., Goldstein, S. M., Linderman, K. W., Schroeder, R. G. (2008). The role of culture as driver of quality management and performance: Infrastructure versus core quality practices. Decision Sciences, 39 (4), 671-702.

Olayonwa, G. O., Iman, A. H. M., Ismail, S. (2012). Office quality classification theoretical and empirical issues. International Journal of strategic property management, 16 (2), 126-142.

Pabedinskaitè, A., Vitkauskas, R. (2010). Quality management tools: analysis of Lithuanian enterprises. The 6th International Scientific Conference Business and Management 2010: selected papers. May 13-14, 2010. (2), 905-912. Vilnius: Vilnius Gediminas Technical University.

Pabedinskaite, A., Vitkauskas, R. (2011). The implementation of quality management principles in Lithuanian enterprises. Economics and management, 16, 252-257.

Rocha, M., Searcy, C., Karapetrovic, S. (2007). Integrating sustainable development into existing management systems. Total Quality Management and Business Excellence, 18 (1-2), 83-92.

Rönnbäck, A., Witell, L. (2008). A review of empirical investigations comparing quality initiatives in manufacturing and service organizations. Managing Service Quality, 18 (6), 577-593.

Sampaio, P., Saraiva, P., Rodrigues, A. G. (2009). An analysis of ISO 9000 data in the world and the European Union. Total Quality Management and Business Excellence, 20 (12), 1303-1320.

Talib, F., Rahman, Z., Qureshi, M. N. (2011). Prioritising the practices of total quality management: An analytic hierarchy process analysis for the service industries. Total Quality Management \& Business Excellence, 22 (12), 1331-1351. 
Tapiero, C. S. (2006). Strategic quality assurance. Journal of Business Economics and Management, 7 (1), 29-35.

Yaacob, Z. (2009). The impact of employee awareness toward quality management thrust on its implementation. European Journal of Economics, Finance and administrative Sciences, 15, 106-116.

Yeung, A. C. L. (2008). Strategic supply management, quality initiatives, and organizational performance. Journal of Operations Management, 26 (4), 490-502.

Zakuan, N. M., Yusof, S. M., Laosirihongthong, T., Shaharoun, A. M. (2010). Proposed relationship of TQM and organisational performance using structured equation modelling. Total Quality Management \& Business Excellence, 21 (2), 185-203.

Zhu, Q., Sarkis, J., Lai, K. H. (2012). Green supply chain management innovation diffusion and its relationship to organizational improvement: An ecological modernization perspective. Journal of Engineering and Technology Management, 29 (1), 168-185. 
